\title{
Research and Construction of University Logistics Services Standardization System
}

\author{
Xiaomei Dai, Xiuli Sang \\ Kunming University of Science and Technology, Institute of Quality Development, Kunming, 650093, \\ China
}

\begin{abstract}
Establish and improve the standardization system contribute to university logistics service and efficient management, adapt to changes in the market economy, improve service quality. Through the existing university logistics services as well as specific analysis of some of the existing standards, combined with series of the establishment of specialized guidance service standard system GB/ T 24421 standards reconstruction university logistics service standardization management system, which has targeted regulate University Logistics service company management practices, work behavior. Finally, a university logistics services company standardized system construction as an example, to build a new university logistics service standardization system basic framework.
\end{abstract}

Keywords: university logistics services; standardization; system.

\section{Introduction}

University Logistics as the support of education, has been great concern, subordinate branch universities gradually become an independent company, its speed of development requires the need for reform management. Socialization of University Logistics prompted the establishment of university logistics services company, which requires colleges and universities logistics enterprise, application of modern management to improve service quality, and standardization system is an effective means of modern management. Hong Dong, Li Xin et al [1]. introduced standardization to university logistics industry, explained some basic introduction of standardized and the meaning and effect of Enforcement of logistics standardization construction, explored the university logistics industry to establish industry-standard system of basic ideas and System Issues, but to build its industry-standard system mostly based on series of standards of GB/T15496, GB/T15497, GB/T15498, the series of standards originated from the Industrial Revolution, as the main emphasis on technical standards, while the service sector is not the case,with the vigorous development of global standardization of services, service industry need to emphasize the "service characteristics", there will be less targeted, not professional classification standards and other issues for the service industry.

In view of this, in order to construct a standard logistics service system more systematic and scientific university logistics service standards to improve the standardization of logistics management, enhance the quality of logistics services, Combining university logistics service features and operational elements, adopt series of standards about services relevant national standards GB/T24421, GB/T15624, GB / T24620, rebuild university logistics service standardization system.

\section{The current situation of logistics services standardization}

Because most colleges and universities to implement administrative management system, centralized management, lacks the necessary autonomy. Therefore, the lack of independence of logistics in our colleges and universities, and less adaptability and initiative, resulting in poor quality of service. Standardization construction, fewer domestic logistics services through the ISO quality certification system, the College's own standardization system even scarcer.

Logistics mode of operation overseas colleges and universities in various countries is different, because the scale of foreign universities is not large, so their management mode of operation is the diversity of flexibility. Their decentralized management, unified management, self-management 
business model, leased mode. These modes adapt their universities, are high-efficiency management. Due to high enterprise, standardization construction more perfect.

China has implemented reform of university logistics for many years, there are many colleges and universities logistics agencies become an independent company. But the fact remains that the administration of the school can not flexible development initiative. The formation of a standardized management, improve the standardization system will promote the development of large logistics enterprises.

\section{Structure and content of the standard system}

Combined with specific guidance for the establishment of service standards GB/ T24421, GB/T15624, GB/T24620 series of standards, service standards provided by the service system of common basic standards, service delivery standards system and service guarantee standards system composition. As shown in Fig.1. Services common basic standards system includes service terms, service classification, service mark, logo, service information classification and coding, service standards and service delivery standards preparation and other norms, as well as service organizations carry out services standardization guidelines or guides, Service Guarantee Standards System includes standard service environment standards, unified technical matters related to the provisions of other safety standards, facilities standards, service standards and service process method, Service delivery standards system includes service delivery management and standardized quality control process, service quality standards and other aspects of the service personnel.

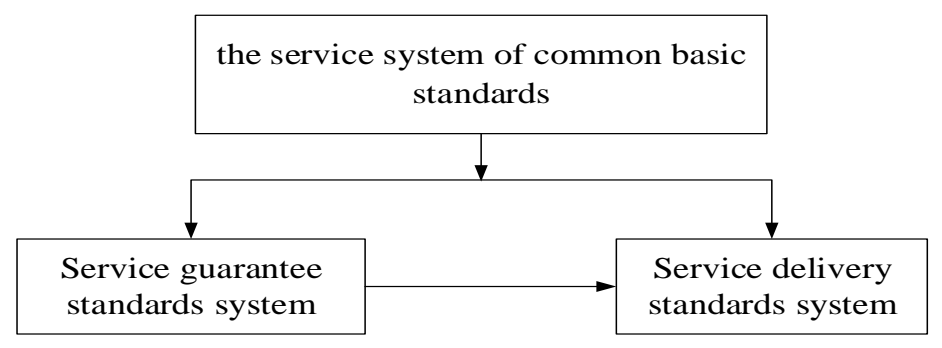

Fig.1 Service standards

\section{University logistics services company Standardization System}

\subsection{Business Profile}

A university logistics services company primarily engaged in a university property management, catering services as well as outsourcing of way in the dispatch and other business projects, of which the share of the property management business accounted for $70 \%$ of the company's business, the share of food service business accounted for 25\%. The company is a typical integrated service-oriented company, is mainly responsible for school staff and students of catering services, sanitation cleaning, green, conservation, supply of water and electricity and utilities and real estate maintenance, student dormitories, classrooms, offices of the guard on duty, to ensure that the normal use of a variety of teaching school production facilities, to provide a good working environment for the teachers and students.

\subsection{Company existing standards}

Companies in the logistics standardization construction has been at the forefront of domestic colleges and universities, is one of the few logistics services through the ISO quality certification system of colleges and universities, has passed the ISO quality management certification, environmental certification system and GB/T28001-2001 Occupational Health and Safety certification system. Logistical services concerned has developed a more comprehensive rules and regulations, such as: "food processing and production management practices," "daily sanitation regulations," "employees work norms", but in the management of the logistics are inevitable showing some lack of quality of service remains to be further enhanced, including the standardization of 
management, lack of standardization system is the main sticking point. Through the advanced experience of standardization system construction, and the formation of deep integration with the universities their own characteristics and then produce a standardized system of internal management and quality of university logistics services to achieve a qualitative leap in the company's top priority.

\subsection{Standardization Framework Figure}

Combined with GB/T24421.2-2009 Services Organization Guide for standardization - Part 2: actual situation and the company's standards, the establishment of the company's logistics standardization system as shown in Fig.2, in the upper range of logistics service standards, enterprise policy objectives, applicable laws, regulations and standardization of regulations. These are the guiding criteria established logistics service standards should comply with legislation, rules and regulations applicable to companies around the enterprise policy objectives. All standard logistics services within the scope of the standard system are under the guidance of this layer standard formation.

Logistics service standards within the scope of the system, including the common basic service standards system, service guarantee standards system and service delivery standards system. These three systems, the common basic service standards system is a cornerstone, the service delivery standards system is the core skeleton, service guarantee standards system providing direct support to service delivery standards system. Three interrelated sub-systems, are indispensable.

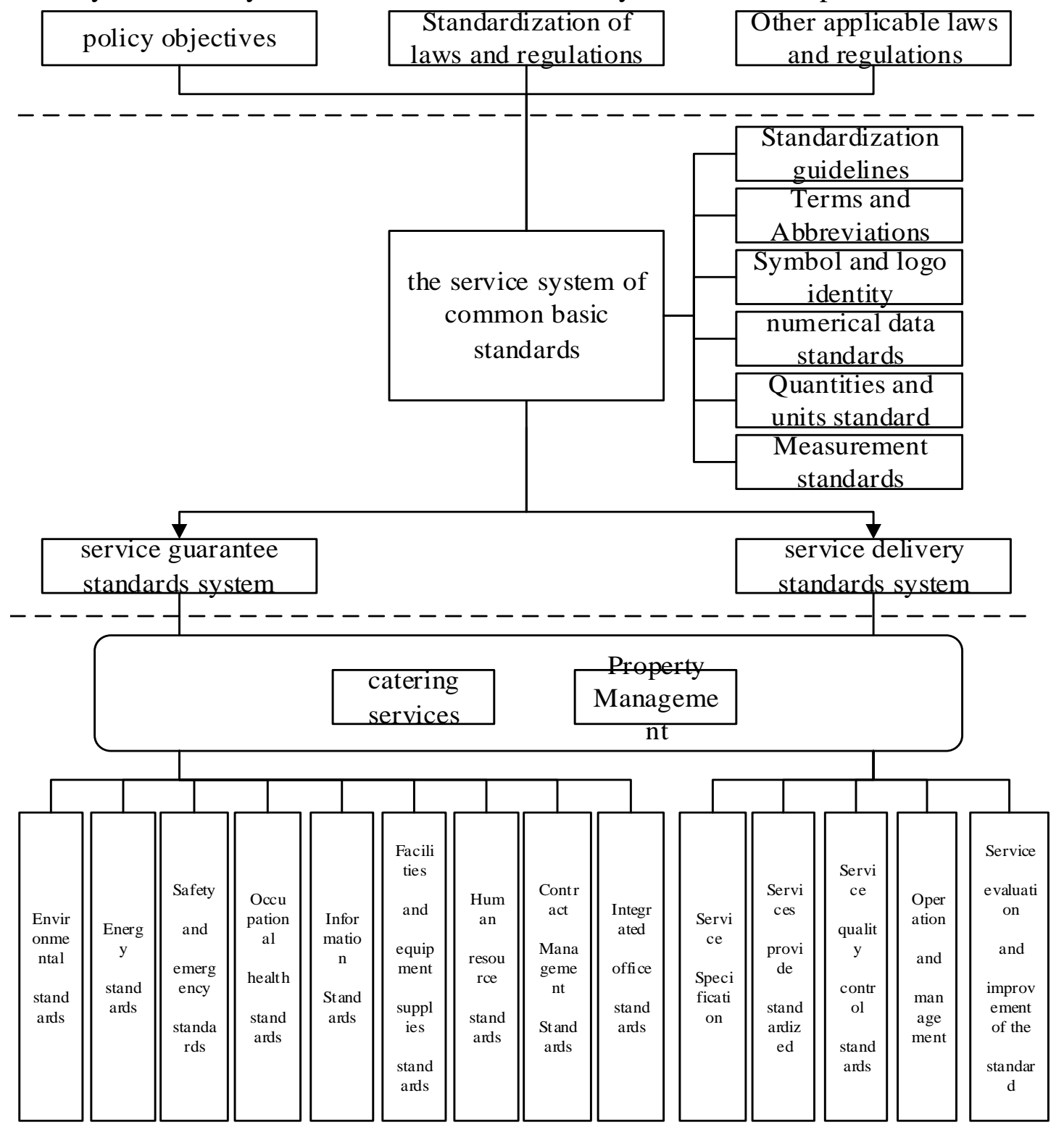

Fig.2 University logistics service standards 


\section{Conclusion}

Based on the research standards and standards prepared on the basis of national standards and the relevant literature, combined with the relevant provisions of the standard system of national standards mentioned in the preparation of the 2009 version of "Organization for Standardization Services Job Guide" and the 2011 version of the "service standardization Guide, "the hierarchy and contents were analyzed, reconstructed university logistics service standards. Systemic reconstructed system, scientific and professional has been further optimized to form an organic whole, is the University Logistics actively implement the national standards, industry standards and local standards, improve the company's service and product quality; established for the company development and growth of the standardization system, establish a good brand image and improve the company's competitiveness; advanced experience combined with the actual situation of the company, to establish a distinctive corporate standards' more appropriate standardized management framework.

\section{References}

[1] Hong Dong, Xin Li. An Analysis of the Application of Standardization in College Logistics [J]. Bulletin of Science and Technology,2007,23(2):297-302

[2] Chongbo Bi. The Research of Heilongjiang Institute of Technology Logistics Standardization System Construction[D]. Jilin University, 2014.

[3] GB/T 24421-2009 Services Organization for Standardization Working Directory

[4] GB/T 15624-2011 Guidelines for standardization of services

[5] Zuming Zhao, Service organization's set of standard system established practice, , China Standard Press 2014 